\title{
An Evaluation of Peak Inspiratory Pressure, Tidal Volume, and Ventilatory Frequency During Ventilation With a Neonatal Self-Inflating Bag Resuscitator
}

\author{
Mariana Almada Bassani RPT MSc, Francisco Mezzacappa Filho MD, \\ Maria Regina de Carvalho Coppo RPT MSc, and Sérgio Tadeu Martins Marba MD PhD
}

\begin{abstract}
BACKGROUND: Although the self-inflating bag is widely used in the hospital setting, variability of delivered ventilatory parameters is usually high, which might result in both hypoventilation and lung injury. The aims of this study were to assess possible sources of the high variability and to evaluate the adequacy of obtained values in relation to the recommended values for neonatal resuscitation. METHODS: This was an experimental study in which 172 health professionals (physicians, resident physicians, physiotherapists, nurses, and nursing technicians) who work with neonatal intensive care manually ventilated a test lung (adjusted to simulate the lungs of an intubated term newborn) with a self-inflating bag in 5 different handling techniques, using 10, 5, 4, 3 , and 2 fingers. Delivered values of peak inspiratory pressure (PIP), tidal volume $\left(V_{T}\right)$, and ventilatory frequency (f) were compared, taking into account the different handling modalities and professions by analysis of variance for repeated measures. Chi-square, the Friedman test and the Fisher exact tests were performed to compare the delivered and standard values. RESULTS: PIP and $V_{T}$ were significantly affected by the handling technique, with higher values for a greater number of fingers used for ventilation. Profession also influenced $V_{T}$ and $f$ significantly: physiotherapists tended to deliver higher volumes and lower rates. Nevertheless, we observed high variability of all studied ventilatory parameters and overall inadequacy of obtained values. Most volunteers delivered excessive pressures and volumes at insufficient ventilatory frequency. CONCLUSIONS: Delivered values seem to depend on operators' individual and professional differences, as well as on the number of fingers used to compress the bag. However, from the clinical point of view, it is important to point out the high occurrence of inadequate delivered values, regardless of handling technique and profession. Key words: cardiopulmonary resuscitation; newborn infant; barotrauma; positive pressure respiration; pulmonary ventilation; tidal volume. [Respir Care 2012;57(4): 525-530. () 2012 Daedalus Enterprises]
\end{abstract}

\section{Introduction}

Self-inflating bags are widely used in the hospital setting, especially for emergency ventilation during cardiopulmonary resuscitation. ${ }^{1-3}$ When used adequately, positive-pressure ventilation is sufficient to resuscitate almost all of apneic or bradycardic newborns. ${ }^{2}$ However, it is well

\footnotetext{
The authors are affiliated with Centro de Atenção Integral à Saúde da Mulher (CAISM), Universidade Estadual de Campinas (UNICAMP), Campinas, São Paulo, Brazil.
}

The authors have disclosed no conflicts of interest. known that manual ventilation with self-inflating bags has limitations, and the literature has not yet established whether or not the benefits are worth the risks. ${ }^{2}$ There is evidence that the ventilatory parameters delivered with this device may be influenced by several factors such as circuit con-

\footnotetext{
Correspondence: Mariana Almada Bassani RPT MSc, Centro de Atenção Integral à Saúde da Mulher (CAISM), Universidade Estadual de Campinas (UNICAMP), Rua Dr Alexander Fleming, 1101 Campinas, São Paulo 13083970, Brazil. E-mail: bassanimariana@hotmail.com.
}

DOI: $10.4187 /$ respcare. 01423 
figuration and brand,, 5 the use of 1 or 2 hands to ventilate, ,46-11 and operator's hand size, ,,7,12 profession, ${ }^{6,13}$ and experience. ${ }^{14}$ This may cause high variability of the absolute values of these parameters, ${ }^{11,15-18}$ causing delivery of either excessive or insufficient values. In the former case the risk for pulmonary injury (barotrauma and volutrauma) is increased, and in the latter there is a higher risk for hypoventilation. ${ }^{11}$ Both situations are potentially harmful to the newborn and might lead to a worse prognosis, longer hospital stay, and development of chronic lung disease.

\section{See the Related Editorial on Page 655}

The aim of this study was to evaluate how peak inspiratory pressure (PIP), tidal volume $\left(\mathrm{V}_{\mathrm{T}}\right)$, and ventilatory frequency (f) are affected by the number of fingers used to compress the self-inflating bag (handling technique) and the operator's profession. We also compared delivered values with those recommended for neonatal resuscitation, and examined the influence of profession and handling technique in the adequacy of the delivered values.

\section{Methods}

This is an experimental study involving health professionals of 5 different groups (physicians, resident physicians, physiotherapists, nurses, and nursing technicians) who work at the Neonatal Intensive Care Unit of the Centro de Atenção Integral à Saúde da Mulher (Center for Integral Attention to Women's Health, CAISM) of the University of Campinas, São Paulo, Brazil. After reading and signing a written consent form, each subject was instructed to manually ventilate a test lung (Adult/Infant Ventilator Tester model VT-2, Bio-Tek, Winooski, Vermont) set with compliance $\left(0.003 \mathrm{~L} / \mathrm{cm} \mathrm{H}_{2} \mathrm{O}\right)$ and resistance ( $200 \mathrm{~cm} \mathrm{H}_{2} \mathrm{O} / \mathrm{L} / \mathrm{min}$ ) levels to simulate the lungs of an intubated term newborn of approximately $3 \mathrm{~kg}$. The test lung complies with the requirements of the American Society for Testing and Materials, F920-93. ${ }^{19}$ A new silicone neonatal self-inflating bag resuscitator (JG Moriya, São Paulo, Brazil) with maximal capacity of $300 \mathrm{~mL}$ was used for ventilation. This self-inflating bag was chosen for this study because it is currently the model most commonly used in our hospital. In these experiments, compressed gas source and reservoir bag were not used. The resuscitator is equipped with a pressure-relief valve set to activate at $40 \mathrm{~cm} \mathrm{H}_{2} \mathrm{O}$ (according to the manufacturer), to prevent the administration of excessive pressures.

The trial setup was based on the method reported by Bassani et al ${ }^{11}$ In summary, all volunteers ventilated manually the test lung with all of the 5 different handling techniques, using 10 fingers (both hands), or only the dom-

\section{QUICK LOOK}

\section{Current knowledge}

Manual ventilation using a self-inflating bag is a common procedure in neonatal intensive care. The optimum technique and monitoring of manual ventilation is unknown.

\section{What this paper contributes to our knowledge}

Regardless of technique or the operator's profession, high airway pressures and high volumes are delivered that were far outside the recommended range. During manual ventilation there is a high variability of delivered tidal volume, peak inspiratory pressure, and respiratory frequency.

inant hand with either $5,4,3$, or 2 fingers to compress the bag. A 1 min interval was allowed between each test condition. All volunteers were blind to their results during the trials, and the sequence of handling techniques was predetermined with a random number table. ${ }^{20}$ Delivered values of PIP, $\mathrm{V}_{\mathrm{T}}$, and f recorded after approximately 5 ventilatory cycles were provided by each subject.

For each ventilatory parameter, 3 categories (high, adequate, and low) were defined based on standard guidelines for neonatal resuscitation. The ranges of values considered as adequate were: PIP $20-25 \mathrm{~cm} \mathrm{H}_{2} \mathrm{O},{ }^{3,21} \mathrm{~V}_{\mathrm{T}} 24-$ $30 \mathrm{~mL}(8-10 \mathrm{~mL} / \mathrm{kg}$ considering a newborn of approximately $3 \mathrm{~kg}$ ), ${ }^{22}$ and f $40-60$ compressions $/ \mathrm{min}^{23}$ This study protocol was approved by the institutional review board of the Faculty of Medical Sciences, Universidade Estadual de Campinas, São Paulo, Brazil.

Statistical analysis was performed using software (SAS System for Windows, version 9.1.3, SAS Institute, Cary, North Carolina). The effects of handling technique and profession on PIP, $\mathrm{V}_{\mathrm{T}}$, and $\mathrm{f}$ were evaluated by analysis of variance for repeated measures, followed by contrast profile and the Tukey post hoc test. Chi-square, the Friedman test, and the Fisher exact test were used to compare delivered and recommended values, considering the different handling techniques and professions. A $P$ value $\leq .05$ was considered statistically significant.

\section{Results}

One hundred seventy-two volunteers of 5 different professional groups were recruited for this study. Fifteen $(8.7 \%)$ were attending physicians, $28(16.3 \%)$ were resident physicians in pediatrics or neonatology, $43(25.0 \%)$ were physiotherapists, $30(17.4 \%)$ were nurses, and 56 $(32.6 \%)$ were nursing technicians. 
Table 1. Ventilatory Variables According to Handling Technique and Profession $(n=172)$

\begin{tabular}{|c|c|c|c|c|c|}
\hline & 10 Fingers & 5 Fingers & 4 Fingers & 3 Fingers & 2 Fingers \\
\hline \multicolumn{6}{|c|}{ Peak Inspiratory Pressure, $\mathrm{cm} \mathrm{H}_{2} \mathrm{O}^{*}$} \\
\hline Nurses & $41.9 \pm 12.9$ & $38.6 \pm 13.5$ & $39.1 \pm 11.9$ & $39.7 \pm 14.1$ & $37.2 \pm 12.4$ \\
\hline Nursing technicians & $45.5 \pm 19.3$ & $40.6 \pm 14.3$ & $40.4 \pm 15.0$ & $39.9 \pm 14.5$ & $39.5 \pm 13.8$ \\
\hline Physicians & $43.8 \pm 13.1$ & $40.4 \pm 8.9$ & $38.3 \pm 10.7$ & $39.9 \pm 12.0$ & $38.9 \pm 8.2$ \\
\hline Resident physicians & $42.4 \pm 17.7$ & $40.4 \pm 15.3$ & $39.9 \pm 15.5$ & $40.2 \pm 11.5$ & $37.9 \pm 12.1$ \\
\hline Physiotherapists & $42.1 \pm 17.1$ & $41.5 \pm 15.5$ & $40.7 \pm 14.9$ & $39.6 \pm 16.7$ & $37.7 \pm 13.1$ \\
\hline \multicolumn{6}{|l|}{ Tidal Volume, $\mathrm{mL} \dagger$} \\
\hline Nurses & $42.2 \pm 12.3$ & $39.5 \pm 13.8$ & $39.3 \pm 11.9$ & $39.8 \pm 11.7$ & $40.4 \pm 15.3$ \\
\hline Nursing technicians & $39.1 \pm 15.1$ & $38.0 \pm 15.0$ & $37.1 \pm 15.1$ & $36.6 \pm 14.1$ & $35.4 \pm 15.7$ \\
\hline Physicians & $38.7 \pm 12.9$ & $38.3 \pm 13.2$ & $36.9 \pm 15.7$ & $37.1 \pm 13.3$ & $37.8 \pm 13.1$ \\
\hline Resident physicians & $37.3 \pm 18.2$ & $35.7 \pm 13.4$ & $34.7 \pm 13.7$ & $35.9 \pm 12.7$ & $32.6 \pm 15.4$ \\
\hline Physiotherapists & $51.1 \pm 19.2$ & $47.6 \pm 18.5$ & $46.4 \pm 16.1$ & $46.4 \pm 15.9$ & $46.6 \pm 15.9$ \\
\hline \multicolumn{6}{|c|}{ Ventilatory Frequency, breaths/min $\ddagger$} \\
\hline Nurses & $45.3 \pm 10.5$ & $45.6 \pm 11.5$ & $45.7 \pm 9.9$ & $45.2 \pm 10.5$ & $41.8 \pm 12.7$ \\
\hline Nursing technicians & $46.2 \pm 19.9$ & $46.9 \pm 15.7$ & $48.4 \pm 19.6$ & $48.5 \pm 20.4$ & $48.4 \pm 17.9$ \\
\hline Physicians & $51.2 \pm 22.4$ & $48.1 \pm 16.6$ & $48.9 \pm 18.6$ & $48.3 \pm 17.6$ & $48.0 \pm 18.3$ \\
\hline Resident physicians & $51.4 \pm 18.2$ & $48.0 \pm 15.6$ & $49.1 \pm 15.0$ & $47.8 \pm 11.9$ & $49.1 \pm 16.4$ \\
\hline Physiotherapists & $31.8 \pm 9.1$ & $32.0 \pm 10.7$ & $32.6 \pm 9.3$ & $32.6 \pm 9.6$ & $32.2 \pm 9.8$ \\
\hline \multicolumn{6}{|c|}{$\begin{array}{l}\text { Values are mean } \pm \mathrm{SD} \text {. } \\
\text { * Main effect of profession } P=.87 \text {. Main effect of the handling technique } P<.001 \text {. Profession } \times \text { technique interaction } P=.58 \text {. } \\
\dagger P \text { Main effect of profession } P<.001 \text {. Main effect of the handling technique } P=.004 \text {. Profession } \times \text { technique interaction } P=.96 \text {. } \\
\ddagger P \text { Main effect of profession } P<.001 \text {. Main effect of the handling technique } P=.50 \text {. Profession } \times \text { technique interaction } P=.29 \text {. }\end{array}$} \\
\hline
\end{tabular}

The handling technique significantly affected PIP $(P<.001)$ and $\mathrm{V}_{\mathrm{T}}(P=.043)$, but not $\mathrm{f}(P=.39)$. Post hoc analysis showed significant increase and decrease of PIP when using 10 fingers and 2 fingers, respectively, compared with the other techniques. Similar results were found for $\mathrm{V}_{\mathrm{T}}$, for which the use of 2 hands (10 fingers) produced significant higher volumes, when compared to the use of one hand.

Profession had an isolated influence on $\mathrm{V}_{\mathrm{T}}(P<.001)$ and $\mathrm{f}(P<.001)$ (Table 1$)$. Physiotherapists delivered significantly higher volumes than attending and resident physicians, and nursing technicians $(P<.001)$, although the $f$ values were lower, compared to all other professional groups $(P<.001)$. Significant interaction between profession and handling technique was not observed for any of the ventilatory parameters.

More importantly, a large discrepancy between the delivered and the current guideline values was observed for all parameters. Regardless of profession or handling technique, 155 out of the 172 participants (ie, 88.4\%) delivered excessive pressures $\left(>25 \mathrm{~cm} \mathrm{H}_{2} \mathrm{O}\right)$, whereas $127(73.8 \%)$ exceeded the recommended range of volume $(>30 \mathrm{~mL})$ (Fig. 1). On the other hand, 85 volunteers (49.4\%) ventilated at insufficient rates ( $<40$ breaths/min) (see Fig. 1). There were no significant effects of the handling techniques on the inadequacy of PIP $(P=.55), \mathrm{V}_{\mathrm{T}}(P=.09)$, and $\mathrm{f}(P=.13)$, regarding the categorized variables. The same was observed with relation to the effects of profession on PIP $(P=.98)$ and $\mathrm{V}_{\mathrm{T}}(P=.051)$. This indicates

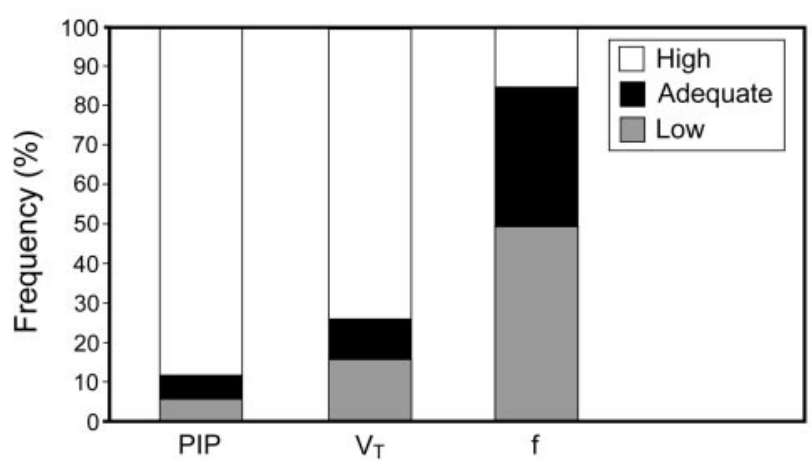

Fig. 1. Percent distribution of categorized values of delivered peak inspiratory pressure (PIP), tidal volume $\left(V_{T}\right)$, and ventilatory frequency $(f)$ during manual ventilation of test lung.

that the great majority of participants of all professional groups delivered excessive pressures and volumes, independently of the number of fingers used for ventilation. However, a significant effect of profession was observed for $\mathrm{f}(P<.001)$. An insufficient number of delivered breaths was generated by most physiotherapists $(81.4 \%)$, as opposed to nurses $(53.3 \%)$, resident physicians $(46.4 \%)$, and nursing technicians $(35.7 \%)$, who achieved adequate rates of ventilation in a higher proportion. Among physicians we observed an equal proportion (26.7\%) of participants who delivered adequate and low f values.

Despite the high pressures and volumes delivered by most volunteers, we observed a high variability of both 
ventilatory parameters. PIP ranged from 2.5 to $103.6 \mathrm{~cm} \mathrm{H}_{2} \mathrm{O}$, and $\mathrm{V}_{\mathrm{T}}$ from 4 to $96 \mathrm{~mL}$. Ventilatory frequency also showed high variability: 4.3 to 54.05 compressions/min.

\section{Discussion}

Over the past 3 decades, evaluation of the self-inflating bag resuscitator has been the goal of a number of published studies, some of which focused on how the resuscitator handling may affect its performance and the potential clinical implications. However, most of these studies were directed to adult patients, ${ }^{4,6-9}$ and only a few of them addressed this aspect in newborns. ${ }^{11,24}$ Ganga-Zandzou et $\mathrm{al}^{24}$ and Bassani et $\mathrm{al}^{11}$ demonstrated that delivered peak pressures are higher when more fingers are used to compress the bag. Bassani et al ${ }^{11}$ observed that this relationship also occurs for $\mathrm{V}_{\mathrm{T}}$, as shown in earlier studies that compared the use of 1 or 2 hands to simulate ventilation in adults. $^{4,6-9}$ These observations are confirmed in the present study with a larger volunteer sample.

Rezende et al evaluated PIP, $\mathrm{V}_{\mathrm{T}}$, and $\mathrm{f}$, during ventilation with self-inflating bag in an analogue neonatal lung model, ${ }^{17}$ as well as in term and preterm newborn sheep. ${ }^{18}$ Both studies showed wide variability of delivered pressures and volumes, which frequently exceeded standard values for safe ventilation. ${ }^{17,18}$ The present study shows that the high variability does not seem to be an artifact due to restricted sample size, because it was still observed even with a considerably greater number of volunteers $(n=$ 172). This is in agreement with the results of Roehr et al, ${ }^{25}$ in which high variability of PIP (2.7-58.9 $\left.\mathrm{cm} \mathrm{H}_{2} \mathrm{O}\right)$ and $\mathrm{V}_{\mathrm{T}}$ (1-14.6 mL) was observed in a sample of 120 volunteers during ventilation of a neonatal mannequin with a self-inflating bag.

We observed that approximately $88 \%$ and $74 \%$ of the participants delivered pressure $\left(>25 \mathrm{~cm} \mathrm{H}_{2} \mathrm{O}\right)$ and volume $(>30 \mathrm{~mL})$ values that are excessive for ventilation of a newborn. We also found that nearly half of the participants delivered breaths at insufficient rates $(<40$ breaths/min), in contrast with the findings by Rezende at al, ${ }^{17,18}$ who showed good adequacy for $\mathrm{f}$. This discrepancy is possibly due to differences in the volunteer population. Rezende et al ${ }^{17,18}$ studied a small group of experienced physicians, whereas we studied a larger sample of subjects from 5 different professions who work with neonatal intensive care, with variable experience in resuscitation.

It is important to point out the possible implications of the present findings, obtained in a heterogeneous sample, especially regarding the high values of PIP and $\mathrm{V}_{\mathrm{T}}$ delivered by over $75 \%$ of the participants, which represent a potential risk for barotrauma and volutrauma, respectively. If the poor adequacy of these isolated variables increases the risk of morbidity and mortality, the combination of excessive ventilatory pressure and volume might be even more harmful. On the other hand, due to the wide variability of the 3 variables, insufficient values of PIP, $\mathrm{V}_{\mathrm{T}}$, and $\mathrm{f}$ might also be delivered. Low pressures and/or volumes may lead to hypoventilation and, consequently, hypoxemia and hypercapnia.

To decrease the variability of ventilatory parameters delivered by the self-inflating bag, some authors suggest the use of a manometer, ${ }^{26}$ which was not tested in our trials. The pop-off valve is another safety item designed to reduce delivered pressures and, consequently, the risk of lung injury. However, some studies showed that the valve may be activated at an inconsistent, wide range of pressures, ${ }^{27}$ frequently exceeding safe values. $^{25,27}$ In the present study, even though the pop-off valve was kept open, we observed peak pressures over $40 \mathrm{~cm} \mathrm{H}_{2} \mathrm{O}$ (the activation pressure limit indicated by the manufacturer) in $52 \%$ of the cases. Kain et al ${ }^{10}$ observed higher levels of PIP when the pop-off valve was kept closed; however, the authors tested different brands of resuscitators and found high variability in PIP and $\mathrm{V}_{\mathrm{T}}$ independently of the position of the valve (opened or closed).

Although the physiotherapists in the present study tended to deliver higher volumes at lower rates, most participants of all professions delivered excessive pressures and volumes, as well as insufficient $\mathrm{f}$ values for the newborn lung model proposed for this study. While our results are in agreement with some previous reports, ${ }^{6,13}$ some studies did not find influence of profession on ventilatory parameters delivered by the selfinflating bag. ${ }^{5,11,25}$ Nevertheless, it is important to stress that it is difficult to compare the results of the several available studies mainly because of differences in the professional profile of the volunteers.

There are limitations to our study. First of all, our tests were conducted in a laboratory environment with a test lung that does not resemble a newborn and does not simulate chest expansion, which is a situation far from the actual clinical setting and may possibly influence volunteers' performance. Additionally, compressed gas source or reservoir bag, which are commonly used for enhancing $\mathrm{F}_{\mathrm{IO}_{2}}$, especially during resuscitation, were not used in the tests. There is evidence that the use of compressed gas in some models of self-inflating bags may influence delivered pressures and volumes. ${ }^{28}$ It has been demonstrated, in $\mathrm{T}$-piece studies, that there is a wide variability of $\mathrm{V}_{\mathrm{T}}$ due to variable inspiratory time. ${ }^{29}$ This indicates that lack of monitoring inspiratory time could contribute to wide ranges of delivered $\mathrm{V}_{\mathrm{T}}$. This may also happen during manual ventilation with the self-inflating bag and may be considered as another limitation to this study. 
An important issue raised in this study is whether or not the self-inflating bag should be used to ventilate a newborn. The answer to this question is quite difficult because, despite the disadvantages that this resuscitator carries regarding patient safety, this equipment is convenient due to its simplicity of operation and transportation, and relatively low cost. Possibly, these advantages contribute to the widespread use of the self-inflating bag in most hospitals all over the world.

Based on the results of this study, one cannot conclude that there is an ideal way of handling the self-inflating bag; however, it is important to stress that this equipment should be used only by well trained personnel, highly aware of its limitations, and in emergency situations.

\section{Conclusions}

The self-inflating bag resuscitator permits a wide range/high variability of delivered pressures, volumes, and ventilatory frequencies, frequently insufficient or excessive for neonatal resuscitation. This may contribute to the occurrence of iatrogenic complications such as barotrauma and volutrauma, as well as hypoventilation, which can increase hospitalization time and costs and, consequently, unfavorable prognosis. An important, clinically relevant finding of this study was that, independently of the profession or the number of fingers used to ventilate, in most instances the target value ranges of ventilatory pressure, volume, and frequency were not attained.

\section{ACKNOWLEDGMENTS}

The authors thank Osvaldo Ribeiro for technical support, Helymar Machado and Dr André Morcillo for statistical analysis, and Dr Rosana Bassani for the valuable suggestions.

\section{REFERENCES}

1. Almeida MF, Guinsburg R. Controversies in neonatal resuscitation. J Pediatr (Rio J) 2001:77(Suppl 1):S41-S52.

2. International Liaison Committee on Resuscitation. 2005 international consensus on cardiopulmonary rescue and emergency cardiovascular care sciences with treatment recommendations. Part 7: Neonatal resuscitation. Resuscitation 2005;67(2-3):293-303.

3. American Heart Association; American Academy of Pediatrics; Universidade Federal de São Paulo; Guinsburg G, Almeida MF, Miyoshi MH, editores. Manual de Reanimação Neonatal, 5th edition. São Paulo: Editora Universidade Federal de São Paulo; 2009:125-238. Book in Portugese.

4. Hess D, Goff G, Johnson K. The effect of hand size, resuscitator brand, and use of two hands on volumes delivered during adult bagvalve ventilation. Respir Care 1989;34(9):805-810.

5. Hussey SG, Ryan CA, Murphy BP. Comparison of three manual ventilation devices using an intubated mannequin. Arch Dis Child Fetal Neonatal Ed 2004;89(3):490-493.
6. Augustine JA, Seidel DR, McCabe JB. Ventilation performance using a self-inflating anesthesia bag: effect of operator characteristics. Am J Emerg Med 1987;5(4):267-270.

7. Hess D, Spahr C. An evaluation of volumes delivered by selected adult disposable resuscitators: the effects of hand size, number of hands used and use of disposable medical gloves. Respir Care 1990; 35(8):800-805.

8. Hess D, Goff G. The effects of two-hand versus one-hand ventilation on volumes delivered during bag-valve ventilation at various resistances end compliances. Respir Care 1987;32(11):1025-1028.

9. Hess D, Simmons M, Blaukovitch S, Lightner D, Doyle T. An evaluation of the effects of fatigue, impedance, and use of two hands on volumes delivered during bag- valve ventilation. Respir Care 1993; 38(3):271-275.

10. Kain ZN, Berde CB, Benjamin PK, Thompson JE. Performance of pediatric resuscitation bags assessed with an infant lung simulator. Anesth Analg 1993;77(2):261-264.

11. Bassani MA, Mezzacappa Filho F, Coppo MRC, Marba STM. Peak pressure and tidal volume are influenced by how the neonatal selfinflating bag is handled. J Pediatr (Rio J) 2009;85(3):217-222.

12. Law GD. Effect of hand size on $\mathrm{V}_{\mathrm{E}}, \mathrm{V}_{\mathrm{T}}$, and $\mathrm{FiO}_{2}$ during manual resuscitation (abstract). Respir Care 1982;27(10):1236-1238.

13. Finer NN, Rich W, Craft A, Henderson C. Comparison of methods of bag and mask ventilation for neonatal resuscitation. Resuscitation 2001;49(3):299-305.

14. Denehy L. The use of manual hyperinflation in airway clearance. Eur Respir J 1999;14(4):958-965.

15. McCarren B, Chow CM. Manual hyperinflation: a description of the technique. Aust J Physiother 1996;42(3):203-208.

16. Turki M, Young M, Wagers SS, Bates JHT. Peak pressures during manual ventilation. Respir Care 2005;50(3):340-344.

17. Rezende JG, Menezes CG, Paula AMC, Ferreira ACP, Zaconeta CAM, Silva CAM, et al. Avaliação do pico de pressão e de frequência respiratória durante o uso de balão auto-inflável em um modelo de pulmão neonatal. J Pediatr (Rio J) 2006;82(5):359-364. Article in Portugese.

18. Rezende JG, Zaconeta CAM, Ferreira ACP, Silva CAM, Rodrigues MP, Rebello CM, Tavares P. Avaliação do pico de pressão, do volume corrente e da frequência respiratória durante ventilação de carneiros prematuros, utilizando balão auto-inflável. J Pediatr (Rio J) 2006;82(4):279-283. Article in Portugese.

19. American Society for Testing and Materials. Standard specifications for performance and safety requirements for resuscitators intended for use with humans. Designation: F920-93. Philadelphia: ASTM; 1999. (Withdrawn 2007)

20. Paradine CG, Rivett BHP. Métodos estatísticos para tecnologias. São Paulo: Polígono da Editora da Universidade de São Paulo, 1974;337. Article in Portugese.

21. Wyllie J. Resuscitation of the term and premature baby. Paediatr Child Health 2008;18(4):166-171.

22. Spitzer AR, Fox WW. Positive-pressure ventilation: pressure-limited and time-cycled ventilators. In: Goldsmith JP, Karotkin EH, editors. Assisted ventilation of the neonate. Philadelphia: Saunders;1996: 167-186.

23. Guinsburg R, Almeida MFB, Miyoshi MH. Reanimação do recémnascido em sala de parto. In: Kopelman BI, Santos AMN, Goulart AL, Almeida MFB, Miyoshi MH, Guinsburg R, editores. Diagnóstico e tratamento em neonatologia. São Paulo: Atheneu; 2004:31-37. Book in Portugese.

24. Ganga- Zandzou PS, Diependaele JF, Riou Y, Klosowski S, Rakza T, Logier R, Lequien P. La ventilation à Ambú chez nouveau-né: une simple question de doigté? Arch Pédiatr 1996;3(12):1270-1272. Article in French. 
25. Roehr CC, Kelm M, Fischer HS, Bührer C, Schmalisch G, Proquitté $\mathrm{H}$. Manual ventilation devices in neonatal resuscitation: tidal volume and positive pressure-provision. Resuscitation 2010;81(2):202-205.

26. Goldstein B, Catlin E, Vetere J, Arguin L. The role of in- line manometers in minimizing peak and mean airway pressure during the hand-regulated ventilation of newborn infants. Respir Care 1989; 34(1):23-27.

27. Finer NN, Barrington KJ, Al-Fadley F, Peters KL. Limitations of self-inflating resuscitators. Pediatrics 1986;77(3):417-420.
28. Godoy AC, Vieira RJ, De Capitani EM. Alterações de pico inspiratório e do volume corrente fornecidos por reanimadores manuais com balão auto-inflável em função do fluxo de entrada de oxigênio utilizado. J Bras Pneumol 2008;34(10):817-821. Article in Portugese.

29. Mc Hale S, Thomas M, Hayden E, Bergin K, Mc Callion N, Molloy EJ. Variation in inspiratory time and tidal volume with T-piece neonatal resuscitator: Association with operator experience and distraction. Resuscitation 2008;79(2):230-233.

This article is approved for Continuing Respiratory Care Education credit. For information and to obtain your CRCE

(free to AARC members) visit

www.RCJournal.com 